\title{
Tercer paisaje y Jardín de la resistencia en los escombros de la revuelta en Santiago de Chille*
}

\section{Francisca Márquez ${ }^{* *}$ \\ Margarita Reyes***}

Se reflexiona sobre el proceso de construcción del jardín de la resistencia en la Estación de Metro Baquedano, espacio urbano transformado en epicentro de las movilizaciones sociales ocurridas desde el 18 de octubre 2019 en Santiago de Chile. A partir del trabajo de observación etnográfica, se describe el proceso de organización social que conduce a la elaboración de este jardín y se analizan las dimensiones que este espacio de naturaleza ofrece a la construcción de un tercer paisaje en medio de la ciudad, esto es, un paisaje donde las plantas nativas, medicinales y espontáneas crecen en medio de los escombros (metro), y que opera como metáfora de la explosión de ira y la violencia desplegada en los meses que dura la protesta. Entre escombros, grafitis, acciones de arte y la toxicidad de la revuelta, la vegetación crece para conmemorar a los caídos y recordarnos la cualidad resiliente de la vida y que, como todo tercer paisaje, este es un espacio que no expresa ni el poder ni la sumisión a este, por lo que permite construir una comunidad emocional desde la rebeldía y la belleza. Se concluye que, como fragmento irresoluto, el jardín abre la posibilidad de que la naturaleza tome protagonismo y proponga un nuevo orden, una evolución conjunta, recíproca y horizontal de los seres que lo habitan en medio del desorden y borramiento en el centro de la ciudad.

Palabras clave: movilización social, resistencia, tercer paisaje, jardín. doi 10.11144/javeriana.mavae17-1.tpes

Fecha de recepción: 17 de junio de 2021

Fecha de aceptación: 6 de septiembre de 2021

Disponible en línea: 1 de enero de 2022

* Artículo de investigación. Este artículo reúne resultados del proyecto de investigación Ruinas urbanas: Réplicas de memoria. Fondecyt 1180352, IR Francisca Márquez. Agradecemos la colaboración de los vecinos del cabildo Barrio Seminario.

** Antropóloga por la Universidad de Chile y doctora en Sociología por la Université catholique de Louvain. Profesora titular del Departamento de Antropología de la Universidad Alberto Hurtado.

ORCID: 0000-0002-9479-0001.

Correo electrónico: fmarquezb@gmail.com.

*** Arquitecta paisajista por la Universidad Central de Chile y magíster en Jardinería y Paisajismo por la Universidad Politécnica de Madrid. Miembro de la Corporación Patrimonio y Paisaje y coordinadora del Nodo Paisajes Ancestrales de la Iniciativa Latinoamericana del Paisaje (LALI).

ORCID: 0000-0001-5099-1162.

Correo electrónico: margaritareyes@gmail.com.

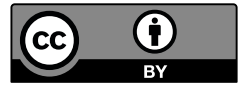




\section{Third Landscape and Garden of Resistance in the Ruins After the Protests in Santiago de Chile}

We reflect about the process of construction of the garden of resistance at the Baquedano Subway Station, an urban space transformed in the epicenter of the social protests that started on 18 October 2019 in Santiago de Chile. Based on the ethnographic observation work, we describe the social organization process that leads to the elaboration of this garden, and we analyze the dimensions that this space of nature offers to the construction of a third landscape in the middle of the city, that is, a landscape where native, medicinal and spontaneous plants grow amidst the ruins (subway), and which operates as a metaphor of the explosion of rage and violence deployed over the months of protest. Among debris, graffiti, artistic actions, and the toxicity of the protest, vegetation grows to commemorate the fallen and remind us of the resilient quality of life and how, like any third landscape, this is a space that does not express the power or submission to it, and therefore makes it possible to build an emotional community from rebellion and beauty. It is concluded that, as an unresolved fragment, the garden opens up the possibility for nature to take center stage and propose a new order, a joint, reciprocal, and horizontal evolution of the beings that inhabit it amidst disorder and blurring downtown.

Keywords: social uprising, resistance, third landscape, garden.

\section{Terceira paisagem e Jardim de resistência nos escombros da revolta em Santiago do Chile}

0 artigo reflete sobre o processo de construção do jardim da resistência na Estação de Metrô Baquedano, espaço urbano transformado no epicentro das mobilizações sociais ocorridas desde 18 de outubro de 2019 em Santiago do Chile. A partir do trabalho de observação etnográfica, descreve-se o processo de organização social que conduz à elaboração deste jardim e analisam-se as dimensões que este espaço de natureza oferece para a construção de uma terceira paisagem em plena cidade, ou seja, uma paisagem onde plantas nativas, medicinais e espontâneas crescem em meio aos escombros (metrô), e que funciona como uma metáfora para a explosão de raiva e violência desdobrada nos meses que dura o protesto. Entre escombros, grafite, ações artísticas e a toxicidade da revolta, a vegetação cresce para comemorar os caídos e nos lembrar a qualidade de vida resiliente e que, como qualquer terceira paisagem, este é um espaço que não expressa nem força nem submissão a ela, permitindo assim a construção de uma comunidade afetiva a partir da rebeldia a beleza. Conclui-se que, como fragmento indeciso, 0 jardim abre a possibilidade de a natureza assumir o centro das atenções e propor uma nova ordem, uma evolução conjunta, recíproca e horizontal dos seres que 0 habitam em meio à desordem e ao apagamento no centro da cidade.

Palavras-chave: mobilização social, resistência, terceira paisagem, jardim. 
Paja seca, espigas, mimbre Un camposanto circular regado de orina y cerveza y ese amarilleo crepuscular de quemante carcajada La camanchaca de lacrimógenas aún navega a lo fantasma, a lo caleuche por el Parque Bustamante, por el Fore desciende al Mapocho a lo cascada siniestra

Y los puentes son catacumbas y los patios se llenan de niebla y el hermano muerto llora tras los postes de luz.

— Oda al pasto amarillo de la Plaza de la Dignidad, Sebastián Diez

\section{Introducción}

$>$ En Chile, entre el 18 de octubre de 2019 y el 15 de marzo de 2020, miles de personas salieron a las calles a manifestarse contra el modelo económico y social imperante. En Santiago de Chile, capital del país, plaza Baquedano (renombrada como plaza Dignidad) se transforma en el principal epicentro de estas masivas manifestaciones. Durante casi cinco meses al lugar acudirán jóvenes, estudiantes, trabajadores y pensionados a expresar su profunda ira contra el Gobierno y sus políticas. Las huellas corporales, gráficas y artísticas sobre los muros y monumentos de la ciudad se constituirán en la expresión colectiva de la revuelta social. Una movilización acompañada de fuerte represión y que dejará cerca de 9000 víctimas y más de 460 mutilaciones oculares (INDH 2020).

La génesis del estallido social, sin embargo, comienza cuando un grupo de estudiantes secundarios, luego de subido el pasaje del transporte público, salta los torniquetes del metro en una de las estaciones centrales de Santiago, Estación Universidad de Chile. El 14 de octubre, llaman a "evadir, no pagar, como otra forma de luchar". No era la primera vez que los jóvenes iniciaban movilizaciones, así lo hicieron en 2006 con "la revolución de los pingüinos", estudiantes secundarios, y en 2011 con movilizaciones universitarias y secundarias. Esta vez, el factor gatillante logró expresar y proyectar una subjetividad colectiva alojada en la sociedad. En los meses previos al estallido social, la percepción del abuso y desprecio a las demandas populares por la actual élite gubernamental se había exacerbado. Los miles de rayados, carteles y gritos dan cuenta de una lucha por la dignidad: " ¿y el pueblo dónde está?... está en las calles pidiendo dignidad". Pero no solo la agresión simbólica de las élites horadaron la paciencia social. En el tiempo más largo de la democracia posdictatorial, se habían acumulado historias de abusos especialmente desde grandes empresas, de ahí la expresión "30 pesos eran en realidad 30 años", lo que se leerá en muchos carteles y rayados de los días siguientes. En paralelo a los 
abusos, se palpaba la impunidad (sanciones leves o inexistentes) a los autores. Afirmaciones elitarias, abusos, impunidades y corrupciones tienen como base una desigualdad socioeconómica extrema que es denunciada por la protesta como un modo de reproducción de la sociedad y la economía. ${ }^{1}$ En síntesis, las evidencias permiten señalar que las manifestaciones en parte se explican por factores macrosociales, ya sea por los problemas de la política institucional, ya sea por las brechas de desigualdad; pero ciertamente también por la crisis del vínculo social que se expresa en una desmesura de un modelo social y económico que no pareciera tener límites desde el punto de vista de sus demandas y abusos con la ciudadanía (Araujo 2019).

Para aportar en la comprensión de las demandas de las manifestaciones, esta investigación ahonda en las expresiones sociales y culturales ocurridas en el espacio público de la protesta. Desde la etnografía y la observación participante, se da cuenta de las marcas sobre los muros (grafitis) y las prácticas de un grupo de vecinas y vecinos inspirados en la guerrilla gardening para dar forma al Jardín de la resistencia en el epicentro de las movilizaciones sociales.

La investigación comienza como un trabajo etnográfico y visual a pocos días del 18 de octubre 2019. Como en todo trabajo etnográfico, la observación participante permitió construir un primer registro de las manifestaciones sociales y las transformaciones materiales que la revuelta dejará tras de sí (Márquez et al. 2020). Con el paso de las semanas y los meses, sin embargo, fuimos comprendiendo que las manifestaciones y las materialidades derruidas se superponían y permanecían como cortezas en el tiempo (Didi-Huberman 2017). La protesta se presentaba como un acontecimiento histórico, pero a la vez corporalmente conmovedor donde la responsabilidad política se develaba como un asunto de todos.. Porque, tal como advierten Butler y Athanasiou (2017), "el dilema de ser conmovido por lo que uno siente, ve y entiende, es siempre uno en el que se encuentra al sí mismo transportado hacia otra escena o hacia un mundo social donde uno ya no es el centro" (24).

La fuerza de la protesta y su masividad prolongada en el tiempo nos llevó a pensar en la necesidad de focalizar la mirada en uno de los epicentros de la revuelta, la estación del metro Baquedano, porque "un lugar como este exige a su visitante que se interrogue, en algún momento, sobre sus propios actos de mirada" (Didi-Huberman 2017, 27). Específicamente en las huellas gráficas en los muros y en las puertas del acceso al metro, ${ }^{2}$ y luego en las prácticas desplegadas por los protagonistas de la acción de guerrilla gardening en la jardinera del zócalo de ingreso al metro.

El artículo describe el proceso de organización social que conduce a la elaboración de este jardín y analiza las dimensiones que ofrece a la construcción de un tercer paisaje en medio del paisaje de la protesta y la insurrección (Endres y Senda-Cook 2011), porque, tal como afirma Reguillo (2017), una plaza vacía puede no significar mucho; pero, cuando dicha plaza es ocupada masivamente, puede cambiar el mundo. El paso, sin embargo, de la plaza como paisaje insurrecto a un tercer paisaje no es simple. Esto requiere, como veremos, de agencias y redes de reciprocidad, afecto y energía social (Hirschman 1980), que permitan entretejer en la multitud, sobre todo juvenil, un tercer paisaje en el espacio de lo público, esto es, un paisaje donde las plantas nativas, medicinales y espontáneas crecen en medio de un espacio de escombros (metro) y de grafitis que operan como metáforas y a la vez duelo de la ira y la violencia desplegada en los meses que dura la protesta (Frederick 2009). Un jardín vivo que a su vez permite, junto a una serie de huellas, grafitis y acciones de arte, conmemorar a los caídos y realizar el duelo a través de la potencia de la vida y el poder sanador de la naturaleza, que crece en medio de un espacio en transformación. Entre el escombro y la toxicidad de la revuelta, la vegetación crece para recordarnos que, como todo tercer paisaje, este es un lugar que no expresa ni el poder ni la sumisión a este (Clément 2014), por lo cual permite construir una comunidad emocional de rebeldía, esto es, una comunidad emocional que alienta la recuperación del sujeto y se convierte en un vehículo de recomposición cultural y política. En este sentido, el jardín, en tanto fragmento irresoluto que se ofrece a la contemplación y al goce compartido de la vivencia en medio del desorden y la violencia, contribuye a superar la condición de víctima a través de la recomposición del sujeto como ser emocional (Jimeno 2007) (figura 1). 


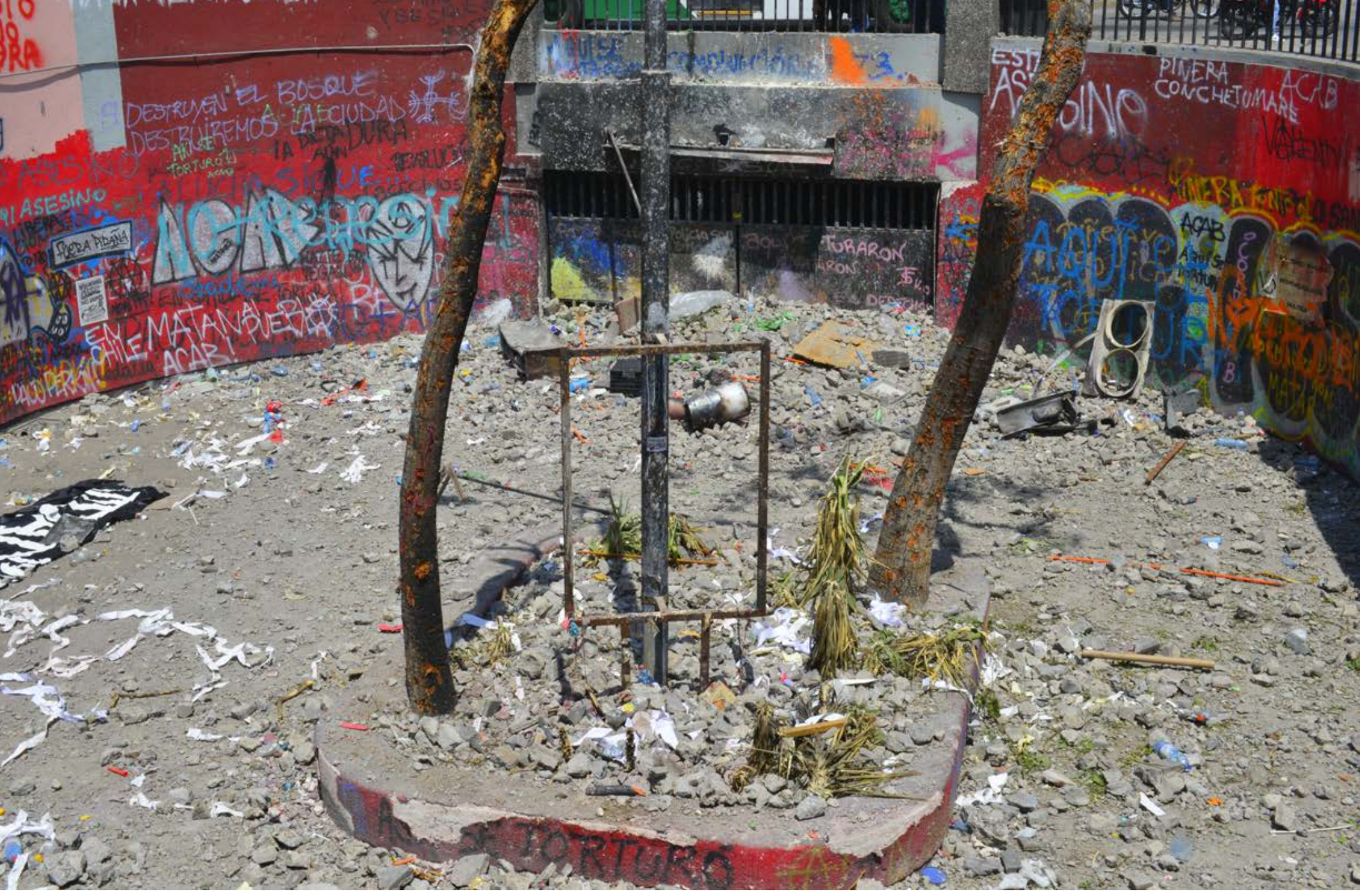

V

V

Figura 1. Álvaro Hoppe Escombros en la estación metro Baquedano tras el estallido social, 2019, fotografía.
Jardín de la resistencia

¿Por qué un jardín en los escombros del metro? ¿Por qué resistencia? Guerrilla gardening, o jardinería de guerrilla, consiste en la toma de un espacio de tierra abandonado o sin un uso definido por ciudadanos para hacer una plantación que lo mejore. Una acción que, por cierto, no cuenta con el permiso de las autoridades, ni necesariamente de las comunidades que viven en el entorno. Actualmente, la jardinería de guerrilla se practica en diferentes países y sus motivaciones son el hermoseamiento de los espacios urbanos o el cultivo comunitario de especies comestibles o agricultura urbana, la mejora del paisaje, la habitabilidad urbana y el fortalecimiento comuniario (Morán y Hernández 2011). ${ }^{3}$ En guerrilla gardening, persiste la acción directa sobre el espacio público, contrariando el orden establecido a través de evitar las burocracias y el poder (Adams, Hardman y Larkham 2014).

Un jardín también que expresa el ideario del tercer paisaje definido como una sutura en un paisaje agreste y urbano: "una sutura que acoge la diversidad ecológica y que perturba los principios del paisajismo domesticado de la planificación urbana dominante" (Clément 2014, 23). Un jardín que irrumpe en el caos del escombro y la devastación de un paisaje que en esa misma destrucción se transforma y vuelve más genuino en relación con su realidad climática (clima mediterráneo), en que el pasto seco en verano es una condición natural. En este escenario, el jardín pasa a ser parte de este nuevo paisaje, a la vez que desconcertar con su vitalidad que invita a sentir la naturaleza como nuestra aliada en este proyecto de sociedad que se desea construir. Un jardín que irrumpe no como expresión e invitación al ocio, sino como un jardín destinado a cultivar la vegetación nativa que habita los cerros que rodean la ciudad, comúnmente ignorada y poco representada en los espacios verdes tradicionales. Asimismo, cultivar aquellas plantas medicinales que ayudarían a reparar la herida de la represión brutal que sucedía en esos días, las mutilaciones y las muertes. 
Tras barajar varias alternativas, se optó por hacer el jardín en el acceso principal al metro Baquedano, una estación de metro transformada en un cúmulo de escombros en cuyo centro aún se reconocía una jardinera. En los muros, grafitis y carteles, denunciaban la represión, la tortura, los muertos y mutilados. Era un lugar destruido, un campo de batalla. Luego de una votación, al final de la búsqueda, se concluyó que ese era el mejor espacio para la construcción del jardín de la resistencia. Pensar y sembrar el jardín en la vertiginosidad de la revuelta se volvía un desafío.

Uno de los problemas que dificultaba poner plantas comestibles era la toxicidad del lugar producto de las bombas lacrimógenas y agua contaminada lanzadas por las fuerzas especiales de la policía. Se decidió entonces sembrar plantas nativas y medicinales. Las plantas nativas entendidas como un símbolo de resistencia por cuanto son plantas adaptadas al clima de Santiago, capaces de aguantar incluso un verano sin riego; pero también como un gesto para la recuperación de la identidad del paisaje, la naturaleza de la precordillera y hacer eco de las muchas demandas medioambientales. Las plantas medicinales, por su parte, permitirían recordar aquellas prácticas populares, campesinas y ancestrales para reparar las heridas, mutilaciones y muertes que la represión dejaba tras de sí. Plantar estas plantas curativas era reconocerse como seres afectados por lo que estaba sucediendo. De ahí que el jardín se transformara también en un espacio conmemorativo de las personas que habían muerto a causa del estallido social. En cada planta, un cartelito con el nombre de uno o más muertos, completaba el homenaje a los caídos en la revuelta. Por último, la forma del jardín sería una espiral que ordenaría el cultivo de las plantas ${ }^{5}$ (figura 3).

Jardinear

La plantación se realizó un domingo de madrugada, es decir, un día con menos fuerzas policiales para así lograr terminar la labor. Quien primero llegó fue un pequeño camión con la donación del compost. Luego, se procedió a sacar la basura y los escombros que había sobre la jardinera y alrededores, latas de cerveza, plásticos, vidrios quebrados y basura que las personas botaban al pasar. Le siguió la preparación del suelo que estaba muy compactado. En la jardinera, se encontraron dos grandes ceibos quemados (Erythrina falcata), ${ }^{6}$ además de unas cuantas plantas de yuca (Yucca sp.), una especie de hojas algo suculentas y espinudas, originaria de Mesoamérica y usada en jardinería. Una vez preparado el terreno, se plantaron las plantas nativas donadas por diferentes viveros; cada una fue plantada en forma de espiral y cuidando que las plantas más altas quedaran en el centro y las más bajas en los bordes.

En el centro, se plantó un palqui (Cestrum parqui), arbusto nativo que, según la tradición popular, es usado para espantar los malos espíritus, bajar la fiebre, como antiinflamatorio, tratar heridas y diversas afecciones de la piel (Muñoz, Montes y Wilkomirsky 2004). En el contexto de este jardín, su uso mágico permitiría proteger el espacio. De ahí nace la consigna del colectivo: "palqui protector del Estado opresor". Junto al palqui, se plantó un natre (Solanum crispum), arbusto endémico de bellas flores azuladas, y al igual que el palqui, de la familia de las solanáceas. Las hojas del natre y sus tallos sin corteza son usados en infusión o decocción para bajar la fiebre, el dolor de cabeza y como hipoglicemiante (MHT 2009). Su sabor es muy amargo, de ahí el dicho "más malo que el natre." Días después, en una actividad de limpieza del espacio, una organización no gubernamental (ONG) aportó una ruda que se plantó en el centro junto al palqui. La ruda (Ruta chalepensis) es una planta originaria del Mediterráneo que, según la tradición popular, espanta a los malos espíritus. Por sus poderosas propiedades y su altura, estas tres plantas fueron puestas en el centro del jardín, de modo de crear una sinergia. 


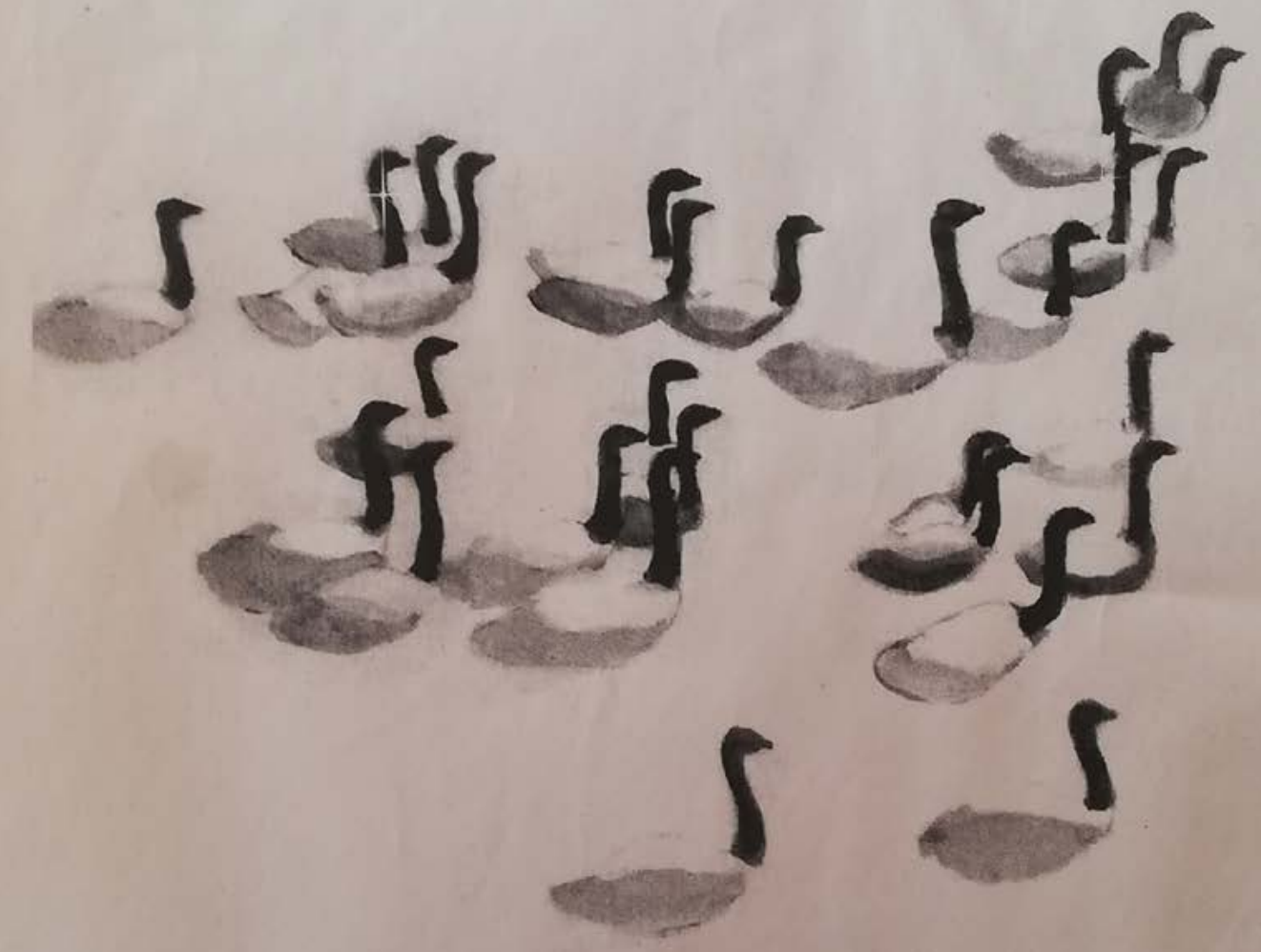

\section{¡LIBEREN EL AGUA DE LOS RÍOS DE LA CORDILLERA!}


Figura 4: Álvaro Hoppe, Jardín de la resistencia, 2020, fotografía.

$\Lambda$

$\Lambda$
Otras plantas medicinales fueron romero (Rosmarinus officinalis) y lavanda (Lavandula dentata). Estas tienen un amplio uso en jardinería, además de en el ámbito culinario, cosmético y medicinal. ${ }^{7}$ Entre las plantas nativas a las que no se le atribuyen propiedades medicinales, pero que sí se recomiendan como plantas ornamentales para jardinería, se utilizaron cacho de cabra (Haplopappus sp.), romerillos (Baccharis spp.), coirón (Pappostipa speciosa) y coironcillo (Nassella chilensis) (ambas gramíneas), chupalla (Eryngium paniculatum), subarbusto nativo de hojas con margen espinoso y de contextura algo suculenta, toronjilcillo (Stachys macraeı) (hierba perenne endémica de Chile, de hojas aromáticas) y maravilla del cerro (Aldama revoluta) (subarbusto endémico, usado en jardines por sus flores amarillas) (Riedemann et al. 2014).

Para asegurar el riego del jardín, se hizo una gestión con la empresa contratada por la municipalidad para regar el sector y un restaurant aledaño para facilitar el agua. Lentamente, el jardín se asentó y creció, aparecieron espontáneamente algunas plantas, incluso tomates que germinando a partir de semillas que traía el compost. Esto integró, aunque no fue la intención inicial, la dimensión del huerto que, históricamente, ha sido el origen de todo jardín (Clément 2019).

Una o dos semanas después de la conformación del jardín, se convocó a una velatón y jornada de limpieza. Era evidente que tras cada manifestación el lugar volvía a llenarse de basura. Había que proteger el lugar en su vocación de memorial del estallido. Los enfrentamientos y la represión cotidiana entre manifestantes y fuerzas represivas dejaban en evidencia que este lugar era un territorio de protesta y lucha social (figura 4).






\section{Arte y conmemoración}

Una vez plantado el jardín, este fue intervenido con acciones de arte en el gran paisaje de la protesta. El borde de la jardinera se pintó y en él se colgaron dos carteles: uno con el nombre "Jardín de la resistencia" y otro que rezaba "Den el agua, liberen el agua de los ríos de la cordillera", realizado por la artista visual Jacinta Reyes. A estas intervenciones se sumó después también un manifiesto que señalaba a quien lo visitara: "La recuperación de la biodiversidad y la apreciación de nuestro paisaje a través de la flora nativa, la sabiduría de los pueblos originarios, la conexión con la tierra y su espiritualidad son ideas vitales del jardín de la resistencia. Buscamos recuperar los espacios naturales que nos pertenecen y hacernos parte de esta democrática verde creación".

Junto a cada planta se instaló un pequeño cartel con los nombres de las personas fallecidas durante la protesta. Los carteles realizados con material reciclado señalan los nombres. El carácter del lugar, sin embargo, provocaba que los objetos y carteles, en general, cambiaran continuamente, algunos desaparecían o se degradaban, otros permanecían y otros llegaban.

Rápidamente, el lugar del zócalo y de la jardinera fueron adquiriendo una impronta de lugar de encuentro y reunión. Además del trabajo del grupo comprometido en el riego y cuidado del lugar, quienes transitaban por el sector se atrevían a descender para observar el jardín, leer los nombres de los muertos, conocer los grafitis, conversar, descansar, sacar fotografías o simplemente compartir. Ya no solo jóvenes se daban el tiempo de estar ahí, también personas mayores con fuerte compromiso y adhesión a la protesta, e incluso turistas. Para muchos de ellos, era conmovedor ver la vida y la naturaleza emerger en medio de la destrucción, un jardín para el disfrute y goce de otros. Tal como señala Roberto (comunicación personal, 11 de agosto de 2020), parte del grupo del jardín:

El jardín de la resistencia viene a significar una reapropiación del espacio y la generación de pertenencia comunitaria, pero con un marcado acercamiento a la protección medioambiental, lo cual, si bien se constituye en un acto humilde y sin gran impacto directo al medio ambiente, se encuentra cargado de simbolismo por el contenido (flora nativa) y el lugar (un espacio de resistencia diario). Por otra parte, su ejecución rescata elementos que dan un vuelco al paradigma imperante y pone en el centro de las relaciones comunitarias la colaboración y el cuidado, donde lo público no está determinado por el Estado ni el Gobierno de turno, sino por los intereses y las necesidades de las comunidades.

Al carácter ecológico y de defensa medioambiental, se le sumó el de espacio memorial. No solo por los pequeños carteles que recordaban a los caídos durante el estallido social, sino también porque el espacio se siguió llenando de pequeños y significativos gestos conmemorativos y performáticos. Como ocurría, incluso antes de la creación del jardín, con las instalaciones de ropa y enaguas que denunciaban los abusos y las violaciones a las mujeres, los ojos de trapo colgados de los ceibos para denunciar las mutilaciones oculares, el gran lienzo con la imagen de una mujer bañada en sangre, el baile ritual de una mujer mapuche en torno a los ceibos, las velas conmemorativas que cada día eran traídas espontáneamente por los visitantes, el cactus plantado con una bandera y un cartel de saludos de la ciudad nortina de lquique, la figura de un pino de cartón con demandas y las réplicas de las estatuillas arcaicas pertenecientes a la cultura Valdivia traídas de regalo desde Ecuador para ser plantadas, nutrir, fertilizar y proteger el jardín (Universidad Alberto Hurtado 2020).

A propósito de estos gestos, Daniela (comunicación personal, 18 de septiembre de 2020), una miembro del cabildo y de la acción del jardín, señala: 
Con motivo de la marcha de la mujer el 8 de marzo 2020, el colectivo propuso una acción que denominó "abracemos las raíces" consistente en envolver las bases de tierra de los árboles de liquidámbar (Liquidambar styraciflua) que habían quedado descubiertas por la destrucción de las jardineras de cemento. Como material para la envoltura, se usaron arpilleras que fueron bordadas con lana. En esta acción, además de las vecinas del cabildo, participaron las Bordadoras de la Resistencia y el Colectivo Lanistería. Entre todas se bordaron las consignas sobre los soportes de arpillera que luego cubrirían las raíces desnudas. Tal como el colectivo señala, en esta acción, se descubría "un gesto maternal en el hecho de cubrir y proteger estas raíces, y la necesidad también de retejer y refundar las raíces de un sistema fundamentalmente patriarcal." Las frases bordadas fueron "abracemos las raíces," "aguas libres," "no más saqueo," "dignidad" "resistencia", “apruebo", “luchar, crear, tejiendo," “sororidad", "econstitución". Los árboles fueron también adornados con coloridos pompones y poemas enviados por poetas desde Antofagasta.

Es interesante el uso de la arpillera en esta acción de arte y cuidado, porque nos remite al paisaje de los testimonios visuales de la dictadura militar chilena. Aunque quienes participan en esta acción son muy jóvenes, no cabe duda de que en este uso y bordado hay mucho de la memoria de las arpilleristas que, al alero de la Vicaría de la Solidaridad, denunciaban los horrores de esos tiempos. Si por paisaje entendemos una construcción visual, política y cultural que otorga densidad espaciorreferencial a los relatos de la memoria, no cabe duda de que el despliegue de estas

Figura 6. Francisca Márquez y Margarita Reyes, Globos oculares en paño colgados del ceibo, jardín de la resistencia, 2020, fotografía.

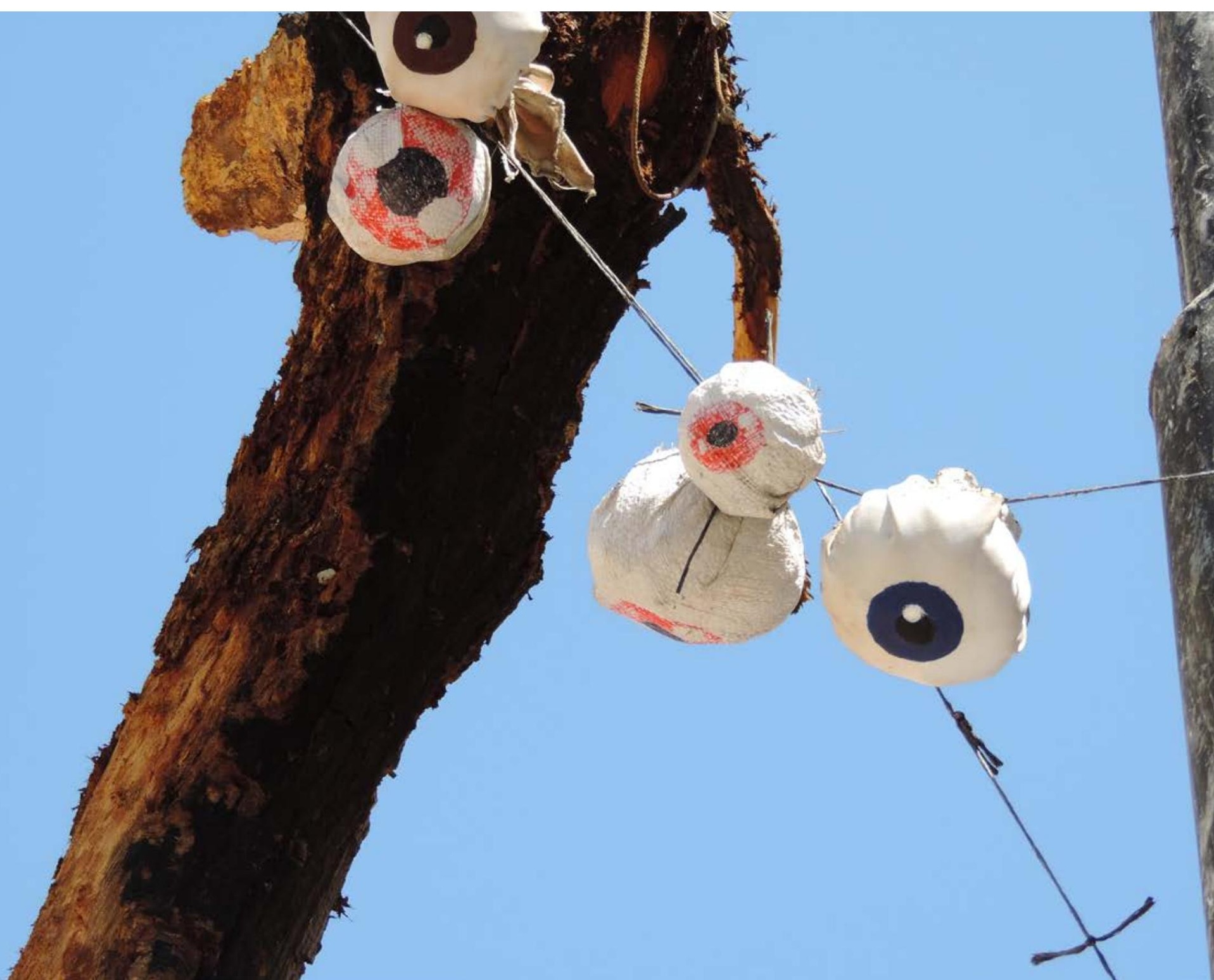


arpilleras sobre las raíces maltratadas de plaza Dignidad tienen toda la fuerza performática de la memoria. Por cierto, el autoritarismo instrumentalizó el paisaje urbano y estético para vehiculizar valores subterráneos y promover la legitimidad del régimen militar (Errázuriz y Leiva 2012; Márquez et al. 2020); pero, paralelamente, la resistencia generó paisajes denotativos, en clave acusatorio-testimonial, que concretizó en múltiples soportes y, en particular, en las arpilleras bordadas. Las arpilleras como dispositivo de evidencia y denuncia vuelven a resurgir frente al paisaje de la protesta y su violencia hacia los humanos y no humanos (figura 6).

\title{
Estrellas y consignas en el zócalo
}

Una otoñal tarde de marzo, en el jardín se instaló Ismael y su perrita chola matapacos. ${ }^{8}$ Con su colchón y algunos objetos, armó su improvisado hogar. La pandemia se había decretado recientemente y plaza Dignidad lucía los estragos del borramiento que las fuerzas policiales habían impuesto sobre muros y monumentos con pintura color camuflaje. "Yo me vengo a vivir acá porque no voy a permitir que nadie lo rompa", decía Ismael a propósito del jardín y las pinturas en los muros. Allí permaneció viviendo durante un mes: “No hay nada más hermoso que levantarse y ver las estrellas (apunta al cielo con los brazos), levantarse y ver 'venceremos', es super rico, entonces como que ese miedo a la enfermedad se te va". Pero no solo las estrellas acompañaban su presencia en el lugar, también estaban los muros con las demandas del movimiento:

\begin{abstract}
Como ustedes están viendo alrededor de sus murallas hay arte, hay mucho arte, mucha memoria, mucha huella de lo que ha pasado acá. De cuarenta y tantos muertos, cuántos cabros jóvenes nuestros, juventud nuestra con un ojito menos, hay algunos casos que hay dos ojitos menos. Y eso es muy triste porque eran jóvenes. Entonces aquí hay mucho de eso, mucho de eso escrito. Sobre todo, lo fundamental, tenemos este gran jardín. Aquí hay vida, ustedes se dan cuenta, aquí hay tomatitos, entonces, es todo, es una zona cero espectacular, de muchos sentimientos encontrados. (figura 7)
\end{abstract}

Ismael no se equivoca, en el jardín de la resistencia abundan las plantas, pero también los grafitis. En efecto, tras el estallido social y la destrucción de la estación del metro, no hay superficie que se libre de ser marcada, rayada, quemada o que no exhiba las cicatrices de la revuelta (Candau y Hameau 2004). Convertida en un lugar de enfrentamiento, de detención y sospecha de tortura, la estación Baquedano debió permanecer cerrada hasta la fecha. Sobre los muros del zócalo que rodean al jardín, los grafitis y murales pintados con brocha o aerosol crearon una conversación anónima, efímera y, a veces, perdurable en el tiempo. Como marcas disruptivas, estas huellas gráficas se imponían visualmente con su juego de palabras y frases sueltas descolgadas de un dintel, de un peldaño, de un vidrio trizado o de lienzos ajados sobre los muros. Y tal como ocurre en estos juegos de palabras, una imagen lleva a la otra, como un hilo de conversación (frases, palabras y trazos), cuya trama y desenlace dependerá de la mirada y de la imaginación del observador. Lectura colectiva y solitaria que nos advierte que

siempre habrá espacio pa'escribir: Evade / no estamos en guerra, estamos unidos / sin transar, sin temer, el pueblo va a vencer / Renuncia Piñera / No + Abusos / A.C.A.B. / A.O.A.B. / Carne es muerte, tortura y violación, hazte vegano / Platón dijo: Ladrón que roba... / 18 muertos / Nueva Constitución / ¿Y José Huenante? / Asamblea Constituyente / Justicia para las víctimas de la represión / Wallmapu libre / Lo que le pasa al país es que la solución está en manos del problema. 


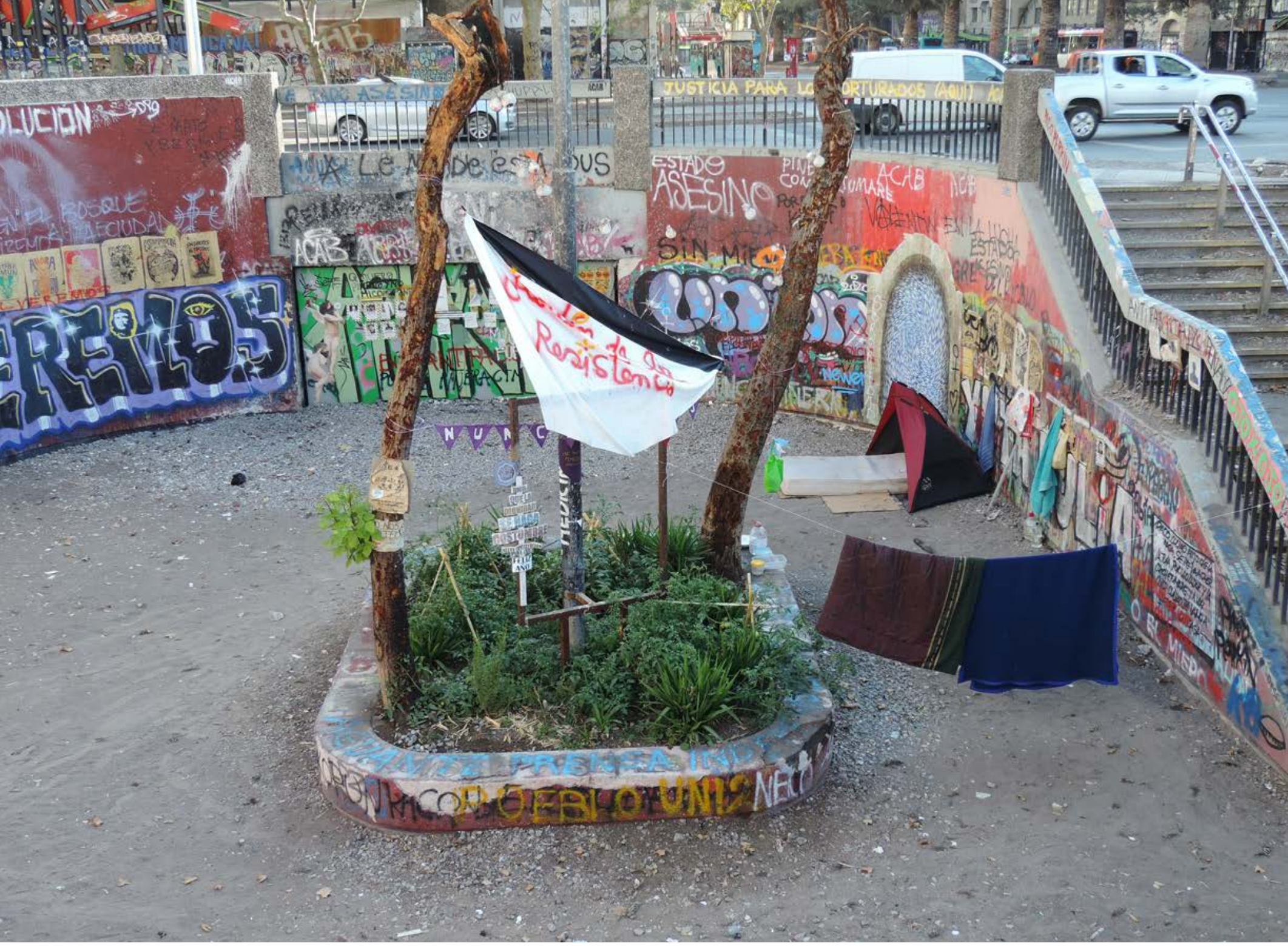

Superposición y disputa gráfica que se acompaña de destrucción y de fuego, como lo que ocurre en las dos grandes entradas del metro; ambas destruidas y luego blindadas servirán de pizarrones para la instalación de grande murales que se sucederán en el tiempo: "Pin8narco (Pinochet Narco) / Dignidad / Lucha Como Mujer / NO + Impunidad". En febrero de 2020, la disputa por los muros del metro se agudiza. En un mes que las mutilaciones oculares sumaban cerca de 600 ojos dañados, se instala un afiche con un glóbulo ocular de tamaño mediano sobre el que se irán añadiendo otros papeles y stickers con consignas que reforzarán la denuncia sobre dichas mutilaciones. Los primeros días de marzo con motivo del 8M se escribirá en color lila la frase "La Paca No Es Compa"9 y otros seis motivos: "Chile Despertó!!!, "a.c.a.b.", "Feliz 1312"," " Mon - Paloma"11 Como ejemplo del respeto entre las brigadas muralistas y el diálogo con la memoria, un mural de gran tamaño permanecerá visible por varios meses: "VENCEREMOS",12 en referencia a la canción de la campaña presidencial de Salvador Allende en 1969. Sobre este mural se colocan a modo de una guarda una serie de afiches en serigrafía con la figura del negro matapacos, la causa mapuche y la fuerza de la mujer en la lucha, todos realizados por el colectivo de jóvenes @serigrafiainstantanea. En marzo, se colocan con esténcil una serie de ojos en alusión a las mutilaciones oculares y una serie de rostros del Che Guevara, respetando siempre la visibilidad del mensaje "VENCEREMOS". El gran mural permanece, pero siempre en diálogo con los acontecimiento e íconos presentes en la protesta (Márquez et al. 2020).

En el zócalo del jardín, transformado en un tercer paisaje, se plasma un mundo soñado que ni el sol ni las estrellas alcanzan para iluminar:

Figura 7. Francisca Márquez y Margarita Reyes, Ruco de Ismael, zócalo del metro, jardín de la resistencia, 2020, fotografía. 
A su manera, los artistas rinden homenaje a los astros y se preocupan por una vibración de la luz que les devuelve el universo. Su jardín no es otro que el espacio multiforme donde se agitan los humanos, sin horizonte definitivo, sin escala precisa y sin límite para el imaginario: el planeta Tierra. Por tanto, hay que mantenerlo protegido y permitir que solo un límite o número de miradas lo vea. (Clément 2014, 36)

Hoy, a casi dos años del estallido social, el jardín resiste prácticamente intacto como un pequeño vergel en medio del cemento y una ciudad clausurada por la pandemia. Uno de los ceibos volvió a brotar, y el que permanece seco luce una tela bordada con la palabra "esperanza" que rodea su tronco. Para los vecinos del cabildo, la esperanza es

Figura 8. Francisca Márquez y Margarita Reyes, Lienzo y ropa en la conmemoración $8 \mathrm{M}$, zócalo metro

Baquedano, 2020, fotografía.

$\Lambda$

$\hat{\Lambda}$ que este espacio se fortalezca como un jardín comunitario, en el que la participación y la relación entre las personas y con la naturaleza, sea lo primordial. Un espacio que dé cabida y sea un espacio de encuentro para las personas. Así también un espacio que guarde la memoria de este movimiento social, de los que han luchado y los que han caído en la lucha por un Chile digno. (figura 8)

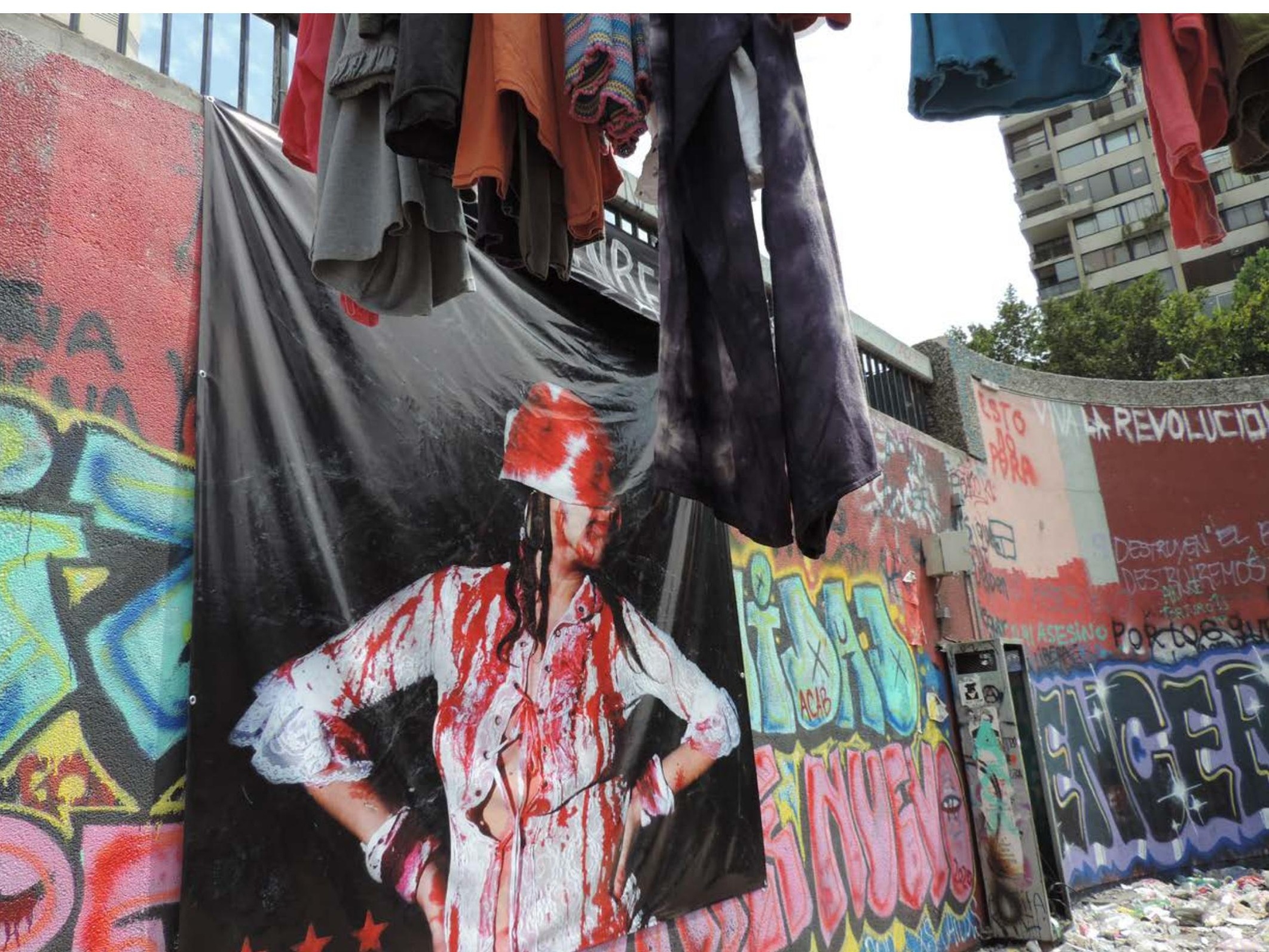




\section{Conclusiones}

Como en todo movimiento social, el estallido del 18 de octubre en Chile desplegó una iconografía y un accionar diverso y propio de la protesta y sus demandas. Con este estudio etnográfico, se logra un registro de uno de los espacios icónicos de la revuelta social: el zócalo del metro Baquedano y el jardín de la resistencia. Analizar las instalaciones, la iconografía, los gestos y las acciones que acompañan esta revuelta social es un camino fructífero para desmontar y desencriptar aquellas voces que se movilizan desde abajo y desde adentro para narrar y reclamar su parte en la historia y en el paisaje de la nación. En efecto, el espacio de plaza Dignidad se convirtió en un denso campo de información para los contrapúblicos subalternos (Fraser 2009). Grafitis y murales dan cuenta de la percepción de desigualdad y una lógica del privilegio que confirman la vigencia de una estructuración jerárquica e inequitativa de la sociedad (Araujo 2019). Tres son las lecciones que podemos extraer de este trabajo de observación:

1. Indignación e idearios. La mejor expresión de la consolidación de este malestar en el paisaje de la protesta son sus muros y monumentos rayados, intervenidos y derruidos; una nueva arquitectura de edificios quemados y blindados, y una nueva monumentalidad cubierta de lienzos y grafitis que, a pesar de la pintura y la limpieza realizada durante la pandemia, aún persisten y convocan. En efecto, en las arenas del zócalo y el cuidado jardín, muchos de los manifestantes ven surgir la posibilidad de reivindicar y soñar nuevos horizontes. En un ejercicio de antropología política de esta iconografía de los muros, hay que reconocer que la expresión del malestar, de la ira y de la desobediencia civil (Thoreau 1970) conviven con la fuerza de las ideas por una sociedad más justa y humana.

Si el despliegue en los muros obedece a una táctica hecha de gestos rápidos y espontáneos para visibilizar el malestar y el sentido de esta lucha en el espacio público, la construcción del jardín, por el contrario, nos habla de gestos lentos, de pausa y cuidado, que necesitan perseverancia y compromiso en el tiempo. Si "el ascetismo gráfico porta la potencia del grito, gestos de aire y de piedra" (Didi-Huberman 2017, 5), la exhuberancia del jardín-vergel nos increpa a la contemplación y el respeto a los tiempos largos del ciclo del brote y de la vida.

Sin embargo, más allá de su evidente función mnemotécnica, ambos actos, los gráficos y los del cultivo, son actos públicos destinados a ser vistos como actos sociales que son, operan como una forma de apropiación y expresión del espacio público urbano (Candau y Hameau 2004). Son prácticas expresivas intersticiales (Campos 2015) que en su emplazamiento logran contornear los dispositivos de vigilancia y control, para hablar desde la emoción y los idearios de transformación social. En estas prácticas políticas, el espacio de lo público es marcado por los manifestantes, y así rompe con el ideario de una ciudad aséptica y ordenada, para posibilitar que ella hable a varias voces. En esta mirada oblicua sobre la historia, la sociedad, la ciudad y la naturaleza, se expresa el acuerdo y el desacuerdo de sentimientos, ideas, conocimientos e ideologías. Un montaje de idearios heterogéneos que a modo de un gran relato discuten para visibilizar el conflicto y el antagonismo como parte esencial de la construcción de una comunidad política. Es la dimensión política del gesto y la expresión performativa que se despliega en el espacio público: "Tal vez la canción de las calles pueda ser entendida como un ejemplo a través del cual un derecho es ejercitado incluso cuando no existe ese derecho, o precisamente porque no existe ese derecho" (Butler 2010, 6). Siguiendo a Hanna Arendt, Butler precisa que el ejercicio de un derecho no es algo que se realiza solitariamente, sino tiene que ser una acción con otros, y debe ser pública para ser visible. Solo así puede asegurarse de que puede ser leída también como el despliegue de una episteme, un modo de transmisión, una realización y un medio de intervenir en el mundo (Taylor 2015). 
2. Por una ontología de la recreación de la naturaleza. En este jardín. lo que está en juego no es solo cómo se entiende la relación entre los seres vivos, sino cómo se la quiere modelar. En el contexto de este jardín vergel que es el jardín de la resistencia, la convivencia de seres humanos y no humanos nos habla de una ontología relacional fundada en un acervo cultural predominantemente indígena, asumiendo que tal ontología ha estado históricamente constreñida por una visión dominante que instala la separación con la naturaleza como mecanismo estructurante de los territorios. Inspirado en esta ontología, el jardín de la resistencia nos propone el camino de la regeneración, idea que apela a la recreación infinita de la vida. La invitación que se nos hace es a repensar la naturaleza como nuestra aliada y a cultivar la creatividad de los actores locales. La regeneración del paisaje para una conservación socialmente inclusiva exige entonces entender las relaciones entre los seres humanos y la naturaleza como un acomodo recíproco, cuyos términos se definen procesualmente. El tránsito desde una economía depredadora hacia formas protectoras de la vegetación y demás especies demanda una lectura atenta de los procesos vividos por quienes pudieron cultivar otros modos de vincularse con el medio. Las formas posibles de integrar seres humanos, árboles y demás especies exigen un contrato en un marco prospectivo de convivencialidad y de buen vivir. Para ello, es menester reconocer el carácter plural y diverso de la vida, pero también la importancia política de estas prácticas (Skewes y Quiroz 2020).

Para los vecinos de la guerrilla gardening, la relación de lo que es humano es comprendida como un vínculo de carácter multidimensional, diverso y plural; cada planta entre los escombros es una lección de ecología urbana. ${ }^{13}$ En esta dinámica, las plantas poseen un importante papel, pues su peculiar agenciamiento permite la conexión con otras formas de existencia, en tanto son actoras e interlocutoras privilegiadas. Como el ceibo quemado que se lo deja permanecer y se lo cubre de cuidados, o las raíces amorosamente abrazadas por las arpilleras, el jardín de la resistencia promueve una antropología de la descolonización de las plantas y su integración en una única esfera de derechos junto a los sujetos humanos y las otras formas de existencia. La naturaleza del jardín y su reproducción enredada en los escombros y la arquitectura nos remite en cierta forma, y tal como lo celebran los grafitis, a ese paraíso del ser-tierra (De la Cadena 2010).

Los mensajes dejados en las murallas del zócalo y en los carteles y lienzos precisan y acentúan la visión del mundo que el jardín, en su conjunto, expresa mediante las formas y escenografías. En su complejidad, el jardín resume a la vez una cosmogonía y un modelo de sociedad. Lejos de ser un adorno del zócalo o un simple paseo público, el jardín de la resistencia acoge los sueños, el descanso y la política (Clément 2014). El jardín, hecho de elementos vivos en diálogo permanente con los vecinos y los actores de la protesta admite la coevolución de los seres de la naturaleza con los humanos afectados. Por ello, con el paso del tiempo, el jardín no deja de cambiar de forma, de asilvestrarse y abrirse a la restauración ecológica y lo ruderal (Stoetze 2018).

3. Del paisaje de la protesta al tercer paisaje. Ciertamente, las protestas portan la capacidad de añadir valor (y destrucción) a ciertos lugares, transformándolos en espacios aptos para congregarse y manifestarse (Endres y Senda-Cook 2011). Allí, en esos espacios de protesta, los usos y las expectativas de los lugares pueden ser transgredidos y abrir temporalmente visiones alternativas a las dominantes. Sin embargo, la repetición y el carácter ritual pueden terminar por normalizar dichos lugares como paisajes de protestas (Turner 1980). El jardín de la resistencia, sin embargo, permite mostrar cómo desde la agencia de jóvenes organizados en cabildos o asambleas se logra agregar un nuevo valor a este paisaje de la protesta y el escombro, para hacer de él un tercer paisaje, esto es, un paisaje que hace de lo residual y de la diversidad que se cobija su materia prima para instalar un memorial para el no olvido; pero, sobre todo, un jardín que contiene una propuesta de regeneración de la vida en la ciudad. Y que como tercer paisaje que es se 
4. A partir del estallido social del 18 de octubre 2019, se organizan cabildos y asambleas en diferentes comunas y regiones del país como organizaciones sociales autoconvocadas, sin adscripción a partidos políticos y con un alto componente de adscripción territorial. Si bien los propósitos y focos de acción de cada cabildo o asamblea pueden ser distintos, se trata de personas que se organizan para hacer comunidad, fortalecer el tejido social y levantar demandas, tanto locales como propuestas ciudadanas con miras a que sean incorporadas en una nueva constitución para Chile. En general, las asambleas y los cabildos han definido valores o principios que los identifican, siendo común encontrar principios como autonomía, democracia participativa y directa, educación popular y poder local, y el rechazo a prácticas violentas.

5. Originalmente la idea fue intervenir la jardinera y también realizar la pintura de un río que bajaría por la escalera oriente hasta llegar al suelo y luego subir a la jardinera enroscándose hasta su centro.

6. El ceibo es un árbol originario del Alto Paraná, en el norte de Argentina (flor nacional de ese país), Paraguay y sur de Brasil, puede llegar a los 20 metros de altura. Sus ramas y semillas son venenosas, contienen un alcaloide que los indígenas utilizaban como droga sedativa y para pescar. Sus flores son comestibles y pueden usarse para teñir telas y sanar dolencias diversas. Cuenta una leyenda guaraní que este árbol conmemora a la mujer indígena abusada por los españoles.

7. El romero es un arbusto muy aromático, originario de las costas rocosas del Mediterráneo y del Cáucaso, usado desde la antigüedad como condimento, planta medicinal para combatir las epidemias, potente aroma para conmemorar a los muertos (Luengo 2008) y como planta mágica para combatir los malos espíritus, el mal de ojos y el mal de amores (González 2002). La lavanda es un arbusto mediano, de hojas y flores muy aromáticas, originario del Mediterráneo y usado en cosmética, jardinería y como planta medicinal. Los tallos con hojas y flores se emplean en infusión como sedante para combatir trastornos nerviosos, malestares estomacales y trastornos menstruales (MHT 2009).

8. El perro matapacos o negro matapacos es el nombre que se le dio a un perro callejero de color negro, que, en el contexto de las marchas estudiantiles de 2011, acompañaba las manifestaciones, ladrando y atacando a las fuerzas policiales. Como un luchador más, se le amarraba un pañuelo rojo en el cuello. El perro matapacos habría fallecido en 2017.

9. La carabinera o mujer policía no es una compañera (en la lucha feminista).

10. $1312=$ a.c.a.b. $=$ All caps are bastard .

11. En alusión a las cantantes chilenas Mon Laferte y Paloma Mami.

12. Venceremos, Quilapayún, 1969: Desde el hondo crisol de la patria / Se levanta el clamor / popular, / Ya se anuncia la nueva alborada, / Todo Chile comienza a cantar. / Recordando al soldado valiente / Cuyo ejemplo lo hiciera inmortal, / Enfrentemos primero a la muerte, / Traicionar a la patria jamás. / Venceremos, venceremos, / Mil cadenas habrá que romper, / Venceremos, venceremos, / La miseria (al fascismo) sabremos vencer.

13. En una línea similar, la historia del perro "Matapacos" es también una poderosa herramienta de ecología urbana, pues "ayuda a evidenciar la poderosa alianza de esas alianzas de seres vivientes que desde su cotidianidad marcan nuevos espacios de encuentro, politización y protección mutua. Todo se inició desde aquel anónimo negro callejero que circulaba libre por la ciudad, como un salvaje en las grandes alamedas. Pero que en medio de este tránsito, también recibió el cariño de señoras y jóvenes que le dieron una espacialidad colectiva de vivir y compartir, libremente. Una protección libre y mutua que convirtió su negro y ágil cuerpo canino como la pieza más viva y genuina de la protesta." (Skewes y Quiroz 2020).

14. A dos dias de las elecciones presidenciales jóvenes de izquierda cubren el Jardín de la Resistencia con pasto reutilizado tras la acción de "recuperación" de Plaza Baquedano por jóvenes de extrema derecha." 
[REFEREICAGS]

Adams David, Michael Hardman y Peter Larkham. 2014. “Exploring Guerrilla Gardening: Gauging Public Views on The Grassroots Activity". Local Environment: The International Journal of Justice and Sustainability 20, n. ${ }^{0}$ 10: 1-16. https://doi.org/10.1080/13549839.2014.980227.

Araujo, Kathya, ed. 2019. Hilos tensados: Paraleereloctubrechileno. Santiago de Chile: Universidad de Santiago de Chile. https://www.researchgate. net/profile/Kathya-Araujo/publication/340315513_Hilos_Tensados_ Para_leer_el_octubre_chileno/links/5e83c0aaa6fdcca789e58495/ Hilos-Tensados-Para-leer-el-octubre-chileno.pdf.

Butler, Judith. 2010. Cuerpos que importan: Sobre los límites materiales y discursivos del "sexo". Buenos Aires: Paidós.

Butler, Judith y Athena Athanasious. 2017. Desposesión: Lo performativo en lo político. Buenos Aires: Eterna Cadencia.

Campos, Ricardo. 2015. "Youth, Graffiti, and the Aestheticization of Transgression". Social Analysis 59, n. ${ }^{0}$ 3, 17-40. https://doi. org/10.3167/sa.2015.590302.

Candau, Joel y Paul Hameau. 2004. "Cicatrices murals: Les graffiti de prison". Le Monde alpin et rhodanien: Revue régionale d'ethnologie 32, n. ${ }^{0} 1-2: 7-11$.

Cepal (Comisión Económica para América Latina y el Caribe). 2017. “Estudio económico de América Latina y el Caribe 2017: La dinámica del ciclo económico actual y los desafíos de política para dinamizar la inversión y el crecimiento". https://www.cepal.org/es/ publicaciones/42001-estudio-economico-america-latina-caribe-2017la-dinamica-ciclo-economico-actual

Clément, Gilles. 2014. Manifiesto del tercer paisaje. Barcelona: Gustavo Gili.

Clément, Gilles. 2019. Una breve historia del jardín. Barcelona: Gustavo Gili.

Criado-Boado, Felipe y Daniel Barreiro. 2013. "El patrimonio era otra cosa”. Revista Estudios Atacameños: Arqueología y Antropología Surandinas, n. ${ }^{0}$ 45: 5-18. http://dx.doi.org/10.4067/S0718-10432013000100002.

De la Cadena, Marisol, ed. 2010. Indigeneidades contemporáneas: Cultura, política y globalización. Lima: Institut français d'études andines.

Didi-Huberman, George. 1997. Lo que vemos, lo que nos mira. Buenos Aires: Manantial.

Didi-Huberman, George. 2017. Sublevaciones. Buenos Aires: Universidad Nacional de Tres de Febrero.

Endres, Danielle y Samantha Senda-Cook. 2011. "Location Matters: The Rhetoric of Place in Protest". Quarterly Journal of Speech 97, n. ${ }^{\circ} 3$ : 257-282. https://doi.org/10.1080/00335630.2011.585167.

Errázuriz, Luis y Gonzalo Leiva. 2012. El golpe estético: Dictadura militar en Chile, 1973-1989. Santiago de Chile: Ocho Libros.

Fraser, Nancy. 2009. Scales of Justice: Reimagining Political Space in a Globalizing World. Nueva York: Columbia University Press.

Frederick, Ursula. 2009. "Revolution is the new black: Grafiti/Art and Mark-making Practices". Archaeologies: Journal of the World Archaeological Congress 5, n. ${ }^{0}$ 2: 210-237. https://doi.org/10.1007/ s11759-009-9107-y.
González, Raúl y Francisca Márquez. 2019. “Chile: De los subterráneos al protagonismo, ¿ocaso del modelo neoliberal?". https://www. iade.org.ar/noticias/chile-de-los-subterraneos-al-protagonismoocaso-del-modelo-neoliberal.

González, José de Vicente. 2002. Boticas monásticas, cartujanas y conventuales en España. Santa Comba Coruña: Resctres.

Hirschman, Albert. 1980. El avance en colectividad: Experimentos populares en la América Latina. México: Fondo de Cultura Económica.

INDH (Instituto Nacional de Derechos Humanos). 2020. "Información constatada por el INDH al 31-01-2020". https://www.indh.cl/

Jimeno, Myriam. 2007. "Lenguaje, subjetividad y experiencias de

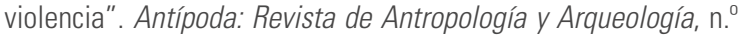
5: 169-190. https://doi.org/10.7440/antipoda5.2007.08.

Luengo L. María Tránsito. 2008. "Flavonoides". Offarm: Farmacia y Sociedad 21, n. ${ }^{\circ}$ 4: 108-113.

Márquez, Francisca, Marcelo Colimil, Daniela Jara, Víctor Landeros y Constanza Martínez. 2020. “Cuando las paredes hablan: Rastros del estallido social en el metro Baquedano, Santiago de Chile". Praxis Arqueológica 1, n. ${ }^{0}$ 1: 98-118. https://doi.org/10.11565/pa.v1i1.10.

Morán Alonso, Nerea y Agustín Hernández Aja. 2011. “Historia de los huertos urbanos: De los huertos para pobres a los programas de agricultura urbana ecológica". En Actas del / Congreso Estatal de Agricultura Ecológica Urbana y Periurbana. Elche. https://oa.upm. es/12201/.

Muñoz Orlando, Marco Montes y Tatiana Wilkomirsky. 2004. Plantas medicinales de uso en Chile: Ouímica y farmacología. 2. ${ }^{a}$ ed. Santiago de Chile: Editorial Universitaria.

MHT (Medicamentos Herbarios Tradicionales). 2009. "103 especies vegetales". https://www.minsal.cl/wp-content/ uploads/2018/02/Libro-MHT-2010.pdf

Reguillo, Rossana. 2017. Paisajes insurrectos: Jóvenes, redes y revueltas en el otoño civilizatorio. México: NED.

Riedemann, Paulina y Gustavo Aldunate. 2014. Flora nativa de valor ornamental. Vol. 1: Identificación y propagación. Chile zona norte. Santiago de Chile: Jardín Botánico Chagual.

Stoetze, Bettina. 2018. Ruderal Ecologies: Rethinking Nature, Migration, and the Urban Landscape in Berlin. Cultural Anthropology 33, n. ${ }^{\circ}$ 2: 295-323. https://doi.org/10.14506/ca33.2.09.

Skewes, Juan Carlos y Rodolfo Quiroz. 2020. "Lecciones del Negro Matapacos". La Raza Cómica. https://razacomica.cl/sitio/ civilizacion-y-barbarie/.

Taylor, Diana. 2015. El archivo y el repertorio: La memoria cultural performática en las Américas. Santiago de Chile: Universidad Alberto Hurtado.

Thoreau, Henry. 1970. Desobediencia civil. Santiago de Chile: Editorial Universitaria. 
Turner, Victor 1980. Selva de los símbolos. Madrid: Siglo XXI.

Universidad Alberto Hurtado. 2020. "Ruinas urbanas". https://ruinasurbanas. cl/2020/04/29/ruinas-urbanas-jardin-de-la-resistencia/ 